\title{
EFFECT OF COLLECTION "NOVOBET" ON METABOLIC PROCESSES AT EXPERIMENTAL DIABETES
}

\section{(C) Sharofova M.U.}

\author{
Institute of Avicenna's Medicine and Pharmacology, Dushanbe, Tajikistan
}

Antidiabetic collection of "Novobet" has created in frame of the treatment systems of Avicenna on the basis of safe medical plants such as roots and rhizomes of Geraniumcollina (Geranium collinum Steph.), Licorice bare (Glycyrrhiza glabra L.) and fruits of sumac tanning (Rhus coriaria L.), taken in pharmacologically compatible proportions.

The purpose of this work was the study of metabolic correcting action of the broth (1:10) "Novobet" in comparison to the collection "Arfazetin."

Material and Methods of the Study. The experiments were conducted over 80 rabbits of both sex with average weighing $1.8-2.5 \mathrm{~kg}$ that were distributed into 4 series of: 1 - intact, 2 - control (not treated) rabbits, which after 18 - hour of starvation once e/r was injected alloksangidrat with the calculation of $80 \mathrm{mg} / \mathrm{kg}$ of the mass of 3 - experimental rabbits, which for $30 \mathrm{~min}$. to injection were injected alloksangidrat and, later, within 30 days daily $a / f$ were injected broth $(1: 10)$ "Novobet" with the calculation of $5 \mathrm{ml} / \mathrm{kg}$ of the weight, 4 - experimental animals, which were injected broth (1:10) "Arfazetin" with the calculation of $5 \mathrm{ml} / \mathrm{kg}$ of the mass. The level of sugar, cholesterol, lipids and MDA of Blood are determined on common methodology.

Results and their discussion. The percent of survival of the animals with diabetes treated within one month by the broth of "Novobet" was $60 \%$. The level of sugar in blood of experimental rabbits treated with broth of "Novobet" in comparison with the untreated series for
7,15 and $30^{\text {th }}$ days of treatment decreased respectively $151,188,131 \%$. The level of general lipids in the composition of blood decreased by $44.5 \%$ against $96.9 \%$ in not untreated series. The level of cholesterol decreased to $32.2 \%$ (in control $217.7 \%$ ). The contents triglycerides decreased to $42.2 \%$ against $110 \%$ in not untreated series. The level of HDL of serum blood increased by $61.5 \%$ in comparison with control series. The level of MDA t serum blood rabbits in the results of conducted course of treatment by "Novobet" decreased to $35.9 \%$ in comparison with not untreated series.

"Arfazetin" defendedanimals from death with alloksangidrat diabetes only by $45.7 \%$. The sugar lowering, lipid-lowering and antioxidant effects of "Arfazetin" were weaker in average from 11 to $41 \%$ than in identical dose of "Novobet."

Conclusion. The manifestation of active hypoglycemic, hypolipidemic and antioxidant actions of "Novobet" is connected with rich content of polyphenols, flavonoids, macro-and microelements, and a number of other BAS included in the composition of collection of medicinal plants.

Conclusions. "Novobet" shows active hypoglycemic, lipidlowering and antioxidant effects. The data obtained allow to recommend "Novobet" for therapy of prediabetes of different genesis of type 2 diabetes of light and average degrees severity and as a supporting remedy for therapy of vascular complications type 1 and type 2 diabetes.

\section{THE SAFETY QUESTIONS OF APPLICATION OF MEDICINAL PLANTS}

\section{(C) Shich E.}

First Moscow State Medical University, Moscow, Russia

Absence of international unification experimental and clinical information, which are characterising the toxic effect of biological active substance, leads to application of prohibited medicinal plants (Aristolochia, Piper methysticum, Sassafras $и$ etc.) in some countries in consequence of difficult side effects. Especially important is evaluation of safety of medicinal plants which causes life threatening side effects or if carcinogenic, hepatotoxic effects experimentally established. Acorus calamus, Aristolochia franchi, Tussilago farfara, Symphytum officinale, Centella asiatica - are medicinal plants with potential carcinogenic effect. However, risk assessment criteria for these plants are not developed. Maximal allowable concentrations is established only for some toxic substances. The introduction of maximal allowable concentrations is an important action in prevention of potential toxic effects of selected medicinal plants. For safety evaluating of medicinal plants is necessary to take into consideration the development of delayed side effects, which are developed during some weeks or months. Such side effects are characteristic of medicinal plants, with hormonal activity, menstrual cycle or blood coagulation system. The commission E (Germany) has considered data for 299 medicinal plants: 
191 - got recommendations for medical application with special indications; 108 - did not get such recommendations because of the absence of the reliable clinical information about the safety, 50 of them are not recommended for medical application, because of their toxicity. Among the medicinal plants, which are not recommended for the medical application by commission, there are some traditional medicinal plants in Russian herbal medicine as such Inula helenium, Angelica arch- angelica, Calendula officinalis, Tussilago farfara, Avena sativa, Paeonia officinalis, Silybum marianum. Published materials of the commission $E$ are formulated as recommendations, but in fact they have regulatory character. Comission $\mathrm{E}$ have paid special attention to diminish the treatment time for some plants with potential toxicity. So, drugs, produced from the natural raw materials, demand the thorough studying with the aim to support the safety of the patients.

\title{
BIOLOGICAL ACTIVE PREPARATIONS FROM HYDROBIONTS
}

\section{(C) Shikov Alexander N., Pozharitskaya Olga N., Makarova Marina N., Makarov Valery G.}

\author{
St-Petersburg Institute of Pharmacy, 47/5, Piskarevsky prosp., 195067, St-Petersburg, Russia
}

The biodiversity of the marine environment and the associated chemical diversity constitute a practically unlimited resource of new bioactive substances. Hydrobionts are living in a very exigent, competitive, and aggressive surrounding which demands the production of quite specific and potent active molecules. Search for new anti-inflammatory, anti-allergic, anti-viral, antibacterial, antihypertensive, immunomodulatory, reparative, cytoprotective etc. substances and methods for their isolation are priorities in the study of hydrobionts. The objects of research are fish, sea urchins, gastropods, krill and other crustaceans, corals and algae. Peptides, polysaccharides, fatty acids, enzymes, vitamins and minerals are the most common isolated active principles. Common methods of processing of hydrobionts are focused in isolation of exact group of active substances. However complex processing of marine organism is open broad perspectives in development of new preparations. Chinoid pigments, chitosan, salts of organic $\mathrm{Ca}$, peptides complex, phospholipids, enzy- matic complex were isolated in results of complex processing of sea urchin. Lipid and hydrophilic complexes were extracted from cod liver. Polyhydroxylated naphtoquinone pigments isolated from sea urchins shells were able to scavenge $\mathrm{DPPH}^{\cdot}$ with $\mathrm{ID}_{50}=0.043-0.057 \mu \mathrm{g}$ according to HPTLC-DPPH test. Pigments in dose of $100 \mu \mathrm{g} / \mathrm{ml}$ have inhibited the grooving of Candida albicans. Peptide-amino acid complex from sea urchin was effective in the treatment of acute rhinosinusitis of rats and showed immunosuppressive properties in mice. The complex of peptides associated with phospholipids from cod liver was studied as anti-inflammatory, reparative and anti-allergic agent for veterinary praxis. Extract of coelomic fluid of sea urchin showed anti-inflammatory and anti-hyaluronidase activity. Sexual activity of rats was increased after single administration of special fraction of sea urchin and mobility and survival was increased after 8 weeks of administration. Hydrobionts are potent sources of biological active compounds with the wide specter of pharmacological activity.

\section{STUDY OF PHARMACOLOGICAL ACTIVITY OF STRONGHYLOCENTROTUS DROEBACHIENSIS EXTRACT ON THE ERECTILE FUNCTION OF YOUNG ADULT MALE WISTAR RATS}

\section{ㄷ Shubin D. V., Ivanova S. A., Makarova M. N.}

Saint-Petersburg Institute of Pharmacy, Russia

Marine natural products have attracted the attention of biologists and chemists of the world over for the last five decades. The gonads of the sea urchins (Stronghylocentrotus droebachiensis) have many types of bioactive compounds and are the good source of pharmacological agents designed to correct disorders of a sexual health of men. The aim of the study was to assess the pharmacological activity of Stronghylocen- trotus droebachiensis extract on the erectile function of young male adult Wistar rats. The Stronghylocentrotus droebachiensis extract was administered per os in doses $1.3,6.4$ and $12.8 \mathrm{mg} / \mathrm{kg}$. There were used two schemes of the experiment: single administration with the reference drug Viagra (sildenafil citrate) (Pfizer, France) and multiple administration during 60 days with the reference drug of plant origin Tentex forte (Himala- 